\title{
COMPARING RESULTS OF TWO DIFFERENT SIZED URETERO-RENOSCOPES IN TREATMENT OF URETERIC STONES
}

\section{General Surgery \\ Dr. Rahul Goel}

Associate prof., Dept. of Gen surgery, Muzaffarnagar Medical College, Muzaffarnagar.

\section{ABSTRACT}

Purpose: To compare success and complications using $6 \mathrm{fr}$ (thin) semirigid URS with $8 \mathrm{fr}$ (standard) semirigid URS in treating ureteric stones. Material \& Methods: Group 1,52 patients treated for ureteric stones with thin URS and the same number treated with standard URS in Group 2 , were compared retrospectively using a matched pair analysis. The size, side, location and impaction of the stones and also the age, gender, body mass index (BMI) and the presence of hydro-uretronephrosis were used as matching parameters, stones were fragmented with pneumatic energy.

Results : The matching parameters were comparable between the 2 groups. The stone free rates were $88.5 \%$ and $84.6 \%$ in group 1 and 2 , mean operative time was $32.7+-5.8 \mathrm{~min}$ and $30.2+-5.4 \mathrm{~min}$ in group 1 and 2 respectively. Post operative haematuria was seen in $1.9 \%$ and $13.5 \%$ patients in group 1 and 2 , Ureteral balloon dilatation was seen in 1.9\% in group 1 as compared to $13.5 \%$ in group 2, Mucosal injury was seen in $1.9 \%$ and $13.5 \%$ in group 1 and 2 respectively .No major complications seen in either groups.

Conclusion: Though stone free status and operative time was similar in both groups, a thin $6 \mathrm{fr}$ URS can reduce the need for ureteric dilatation and has less minor complications as mucosal injury and post operative haematuria in patients.

\section{KEYWORDS}

\section{INTRODUCTION}

Ureterorenoscopy (URS) is widely used in ureteric stone management and like any surgical procedure is associated with complications. The over all complication rate is from $9 \%-25 \%(1-6)$, Intra operative being ( ureteral perforation, mucosal injury, bleeding and ureteral avulsion), Early being fever $1.1 \%$, haematuria $2 \%$ and renal colic $2.2 \%$, late being ureteral strictures and reflux $0.1 \%(2)$, the complications increase with increase in size of instruments (7-8), the over all complications decrease by $5-9 \%$ on using thin instruments, this study is done to compare the ureteroscopic surgical results using thin and standard instruments in treatment of ureteric stones.

\section{MATERIAL \& METHODS}

Between march 2010 and October 2017,104 patients were treated ,52 in each group were treated with thin (6fr karl storz) and standard ( $8 \mathrm{fr}$ karl storz ) URS and outcomes were compared using a matched pair analysis at a 1:1 ratio. The matching parameters were size, side , location and impaction of stones and also the patients age, gender body mass index (BMI) and the presence of hydroureteronephrosis, impaction of stone was as failure to pass the guide wire beyond the stone.

Pre operative evaluation, was done with plain C.T -K.U.B. (stone size was determined by longest diameter on CT KUB), and routine laboratory tests. Patients with multiple stones ,pediatric cases and with anomalies in kidneys were excluded from study.

All procedures were done by single urologist under spinal anaesthesia, and same surgical technique was used in both groups, after passing a guide wire in ureter, ureteroscope was passed in ureter, ureteric orifice was dilated with balloon dilator if passing of URS in the orifice was difficult. The stone was fragmented using pneumatic energy , and retrieved using a stone forceps, at the end of procedure a DJ stent was placed in cases having long duration of surgery or in presence of ureteral trauma.

Treatment success was defined as complete stone clearance confirmed by a plain C.T. KUB one month after surgery.

Both groups were compared with respect to operative time, need for baloon dilation,stone migration rates,post operative stent placement, stone free rates (SFR), length of hospital stay, and auxillary procedures and complication rates.

\section{STATISTICALANALYSIS}

Statistical analysis were performed with SPSS software, version 20.0 ( IBM,Armonk,NY).Data were determined as mean +-SD or frequency. The Kolmogorov -Smirnov test was performed to test normal distribution. Categorical variables were analysed using the chisquared test or fishers exact test, according to the result of the Kolmogorov -smirnov test. Continuous variables were compared with an unpaired $t$ test or the Mann-Whitney $U$ test. A P value $<$ or equal to .05 was considered significant.

\section{RESULTS}

Table 1 : Matched -pair analysis of the groups

\begin{tabular}{|l|l|l|l|}
\hline Variables & $\begin{array}{l}\text { GROUP 1 (6FR: } \\
\mathrm{n}=52)\end{array}$ & $\begin{array}{l}\text { GROUP 2 (8FR: } \\
\mathrm{n}=52)\end{array}$ & P Value \\
\hline Age $(\mathrm{yrs})$ & $43.7+-11.2$ & $44.2+-12.1$ & .820 \\
\hline Male/female & $28 / 24$ & $30 / 22$ & .693 \\
\hline BMI $(\mathrm{Kg} / \mathrm{m} 2)$ & $26.54+-3.49$ & $27.40+-3.31$ & .112 \\
\hline Stone size $\mathrm{mm}$ & $11.5+-2.5$ & $12.2+-2.2$ & .159 \\
\hline Side & $27 / 25$ & $24 / 28$ & .556 \\
\hline Stone location & & & .892 \\
\hline Upper ureter $\mathrm{n} \%$ & 13 & 11 & \\
\hline Mid ureter $\mathrm{n} \%$ & 11 & 12 & \\
\hline $\begin{array}{l}\text { Lower ureter } \mathrm{n} \\
\%\end{array}$ & 28 & 29 & .684 \\
\hline $\begin{array}{l}\text { Pre op } \\
\text { hydronephrosis } \\
\mathrm{n} \%\end{array}$ & 32 & 34 & .767 \\
\hline $\begin{array}{l}\text { Stone impaction } \\
\mathrm{n} \%\end{array}$ & 6 & 7 & \\
\hline
\end{tabular}

The demographic data were comparable between the two groups ( table 1)

\section{Table 2: Operative and Post Operative out comes}

\begin{tabular}{|l|l|l|l|}
\hline \multicolumn{1}{|c|}{ Variables } & Group 1 & Group 2 & P Value \\
\hline Operative time (min) & $32.7+-5.8$ & $30.2+-5.4$ & .06 \\
\hline Balloon dilatation (n,\%) & $1(1.9)$ & $8(15.4)$ & .015 \\
\hline Stent placement (n,\%) & $11(21.2)$ & $13(25)$ & .642 \\
\hline Axillary procedure (n,\%) & $6(11.5)$ & $8(15.4)$ & .42 \\
\hline $\begin{array}{l}\text { SFR after a single } \\
\text { procedure(n/total;\%) }\end{array}$ & $46 / 52(88.5)$ & $44 / 52(84.6)$ & .566 \\
\hline Length of hospital stay (days) & $1.15+-0.64$ & $1.21+-0.74$ & .696 \\
\hline
\end{tabular}

The operative and postoperative out comes of patients in each group are shown in table 2. The complications were classified using the Clavien system( 11).The number of patients who experienced any of the complications was higher in group2, though the difference was not statistically significant.

TABLE 3 : The Intraoperative and Postoperative complications

\begin{tabular}{|l|l|l|l|}
\hline Variables & $\begin{array}{l}\text { Group 1 } \\
(52)\end{array}$ & $\begin{array}{l}\text { Group 2 } \\
(52)\end{array}$ & P Value \\
\hline Complication rate (no of patients\%) & $6(11.5 \%)$ & $9(17.3 \%)$ & .085 \\
\hline Fever (n,\%) & $3(5.8)$ & $3(5.8)$ & 1.000 \\
\hline Haematuria (n,\%) & $1(1.9)$ & $7(13.5)$ & .027 \\
\hline Renal colic (n,\%) & $2(3.8)$ & $3(5.8)$ & .647 \\
\hline Mucosal injury (n,\%) & $1(1.9)$ & $7(13.5)$ & .027 \\
\hline Stone migration (n,\%) & $2(3.8)$ & $3(5.8)$ & .647 \\
\hline Inability to introduce the URS(n,\%) & $1(1.9)$ & $3(5.8)$ & .112 \\
\hline Residual fragments(n,\%) & $3(5.8)$ & $2(3.8)$ & .647 \\
\hline
\end{tabular}


In patients of stone migration a double $\mathrm{J}$ stent was placed and auxiliary procedure such as shock wave lithotripsy, retrograde intra renal surgery(RIRS) or re-URS was performed.

In patients with inability to introduce URS a double $\mathrm{J}$ stent was placed and URS repeated after 2 weeks with same ureteroscope.

In patients of residual fragments re URS was done 1 month after surgery. The overall stone free rate was $100 \%$ in both groups after auxiliary treatment.

\section{COMMENT}

Semi rigid URS is the preferred treatment choice for ureteric stone, the reported stone free rate is $85 \%$ to $100 \%$ depending on the stone location. Despite its high success it has 9\%-25\% complication rate both major and minor.it has been reported to have less complications $5 \%-9 \%$ on using small calibre ureteroscopes.

According to our findings on using small $6 \mathrm{fr}$ URS had low incidence of ureteral injury and post operative haematuria and similar SFR and a reduced need for balloon dilatation with this calibre URS.

Yaycioglu et al (10) compared $7.5 \mathrm{fr}$ and $10 \mathrm{fr}$ rigid URS and reported better results with $7.5 \mathrm{fr}$ URS. The SFR were similar in both groups though the complication rates were higher in group $2(10 \mathrm{fr}$ URS).

Stone migration and inability to reach the stone was higher in group 2 , where as residual stone fragment was higher in group 1.

In this study mucosal injury and haematuria were most common complication in group 2, in each group injury was treated with placement of DJ stent, to our knowledge these complications can be reduced by using small calibre URS.(11-12)

Balloon dilatation was needed more in group 2 , and its need can be reduced by using smaller calibre urs.(13)

The disadvantage of thin URS was small working channel leading to poor saline flow leading to poor visibility and the use of thin stone retrieval forceps, in spite of this we did not observe any statistical difference in groups in terms of operative time and SFR .

\section{CONCLUSION}

In this study, the SFR and operative time were similar in both groups, however the thin calibre URS had reduced need of balloon dilation and reduced minor complication such as mucosal injury and haematuria in patients.

\section{REFERENCES}

1. Preminger GM, TiseliusHG, Assimos DG ,et al American urological association education and research, INC European association of urology .2007 guidelines for the education and research, INC European association of urology

2. Geavlete P, Georgescu D, Nita G et al. Complications of 2735 retrograde semirigid ureteroscopy procedure : a single centre experience. .J Endourol .2006:20:179-185

3. Stern JM, Yiee J, Park S. Safety and efficacy of ureteral access sheath. J Endourol.2007;21:119-123

4. Delvecchio FC, Auge BK, Brizuela RM, et al . Assessment of stricture formation with the ureteral access sheath.Urology 2003:61:518-522

5. Matlaga BR, LingemanJE . Surgical management of stones :new technology .Adv Chronic Kidney Dis.2009:16:60-64

6. Monga M, Beeman WW. Advanced intrarenal ureteroscopic procedures .Urol Clinics North America 2004:31:129-135

7. Schuster TG, Hollenbeck BK, Faerber GJ,et al. Complications of ureteroscopy: analysis of predictive factors.JUrol.2001:166;538-540

8. Grasso M, Beaghler M, Loisides P. The case of primary endoscopic management of upper tract calculi II; cost and out come assessment of 112 primary ureteral calculi .Urology .1995:45:372-376

9. Dindo D, Demartines N, ClavienPA . Classification of surgical complication :a new proposal with evaluation in a cohort of 6336 patients and results of a survey .Ann Surg.2004:240:205-213

10. Yaycioglu O, Guvel S, Kilinc F,et al .Results with 7.5 fr versus $10 \mathrm{fr}$ rigid ureteroscope in treatment of ureteral calculi.Urology .2004:64;643-646

11. Mandal S, Goel A, Singh MK ,et al .Clavien Classification of semirigid ureteroscopy complications :a prospective study .Urology .2012:80:995-1001

12. Ather MH, Paryani J, Memon A,et al. A 10 yrs experience of managing ureteric calculi :changing trend towards endourological intervention :is there a role for open surgery? BJU Int .2001:88:173-177

13. Bin X, Friedlander JI, Chuang K,et al . Predictive factors for intraoperative balloon dilation in semirigid ureteroscopic lithotripsy.J Endourol.2012:26:988-991 